\title{
Optimal design of main parameters for automotive power steering units take out oil machine
}

\author{
Guangming $\mathrm{Li}^{1}$, Kai Cheng ${ }^{2}$, Renjiang $\mathrm{Li}^{1}$ \\ ${ }^{1}$ Electrical and Mechanical Engineering Institute, Changchun University of Technology, \\ Changchun, 130012, China \\ ${ }^{2}$ Osaka University, Osaka, 5640053, japan
}

Keywords: Automotive power steering units Orthogonal test Optimal design

\begin{abstract}
Based on the orthogonal test, the optimal design of the main parameters for the automotive power steering units take out oil machine that is The first adding gas time, Adding gas interval and Adding gas time has been completed in order to determine the optimal program to achieve the best pumping effect..
\end{abstract}

\section{Introduction}

Automobile power steering gear is a power-assisted steering mechanism, by which the automobile is able to steer easily. This mechanism is installed in all modern automobiles. Figure 1 is the schematic diagram of hydraulic power steering gear, in which axle $\mathrm{A}$ is connected with the steering wheel, and axle B is connected with steering mechanism. When the automobile needs to turn right, the driver will turn the steering wheel to the right, thus axle A will be drove to rotate. High pressure oil is connected with the left cavity of steering gear through steering control valve, which drive the steering nuts to the right, and then drive axle B to rotate by the cogs on the steering nuts, thus drive the automobile to the right. The working process is just reverse if the automobile needs to turn left.

Acceptance test must be carried on the automobile power steering gear after the final assembly. It is mainly to simulate the practical usage to test its performance, and able to leave factory after passed the test. The steering gear is filled with hydraulic oil after the test, and which should be discharged as required. And then surface cleaning and paint spraying should be conducted, and packaging at last. Oil discharging machine is used to discharge the remaining hydraulic oil in the internal gear.

Automobile power steering gear is a complex mechanism, thus it is necessary to analyze and research its internal structures to successfully eliminate its internal remaining hydraulic oil, especially clear the locations of all oil channels and their corresponding relationships.

\section{Production status of the oil discharging of the automobile power steering gear}

There are many enterprises occupied in manufacturing automobile power steering gear in our country, which are of various types. This paper involves in the hydraulic power steering gear for heavy truck use. According to the industry requirements, performance test must be conducted on products after final assembly, which mainly aims to test the internal discharging and steering force character, etc. The hydraulic oil used in the test can be recycled after filtering and returning to the oil tank of the tester, however, the remaining hydraulic oil in the internal cavity of the power steering gear is far more than the amount that required by the factory leaving requirements. It will not only increase the production costs, but also pollute the production environment due to leakage

At present, there are two methods for the domestic power steering gear manufactures to solve this problem. One is to discharge the oil by blowing, and another is to discharge the oil naturally. Discharging the oil by blowing refers to inflate compressed air into its internal cavity through the outlet, and then rapidly pull out the air nozzle, thus the remaining hydraulic oil will discharge with the air flow. In practical production, each product generally needs to be blown for three times to discharge the oil. Discharging the oil naturally refers to place the tested products upside down, so as to naturally discharge the oil by the weight of the hydraulic oil. As the internal structure of the 
power steering gear is complex, and the diameters of its partial oil channels' inlets and outlets are too small, it is difficult for its internal remaining hydraulic oil to flow out successfully, thus each product must be placed upside down to discharge the oil for 8 hours at least. In order to lessen the remaining hydraulic oil, axle A must be shaken back and forth for 3-4 times at intervals. It can be seen from the enterprises' hydraulic oil consumption that these two methods are unsatisfactory in oil discharging performance. It is found from the practical disassembling 50A automobile power steering gear that the remaining quantity is about $300 \mathrm{ml}$. besides, these two methods are of some drawbacks, for example, the natural oil discharging method is time-consuming. Although discharging oil by blowing is fast, it splashes with the discharging of the air flow, which seriously polluted the production environment, especially some oil splashes in mist, resulting in the whole workshop in oil mist. The workshop covered with oil is harmful to workers' health. In addition, the discharging effectiveness of these two methods is both greatly affected by human factors.

\section{Analysis on the structure and oil channels of the automobile power steering gear}

The internal structure and oil channels of the automobile power steering gear are very complex, which should be made clear to discharge the hydraulic oil successfully.

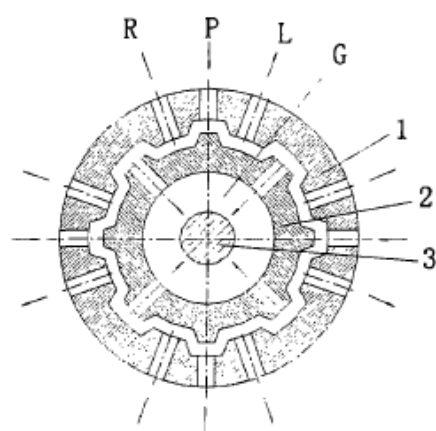

(a) go straight

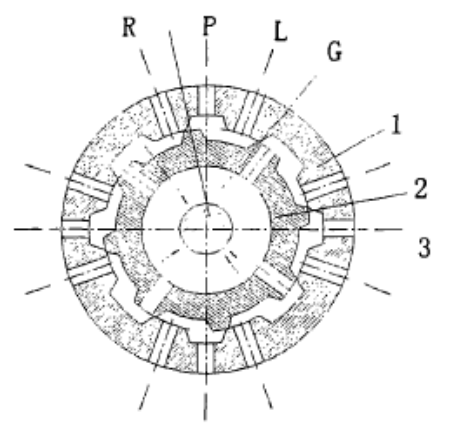

(b) turn left

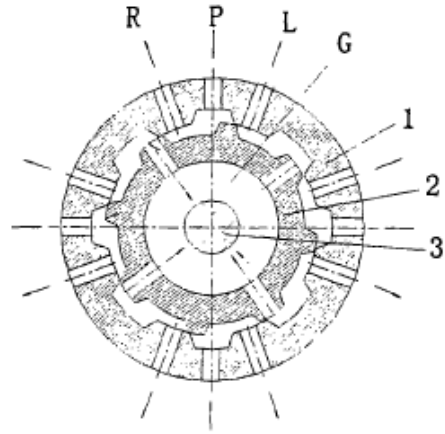

(c) turn right

P-connect to the oil hydraulic pump, R-connect to the turn right power cylinder, L-connect to the turn left power cylinder, G- connect to the oil tank, 1- valve pocket, 2- valve element, 3- torsion bar

Figure 2 schematic diagram of the rotary valve of steering gear

Figure 2 is the schematic diagram of the rotary valve of steering gear, figure (a) is the status of going straight, in which the valve element lies in the middle position, and the hydraulic oil will flow inlet $G$ through inlet $P$ and directly return to the oil tank, and keep in straight status. Refer to the oil channels movement in figure (b) and (c) when the automobile turns left and right. The steering gear stays in the status of figure (a) of figure 2 after the performance test, i.e. all oil channels are in interconnected status.

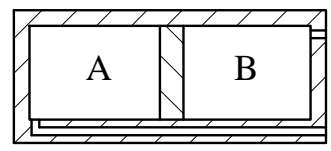

Figure3 Structural diagram of automotive power steering units

Simple graph of the steering gear is shown as figure 3. Only one oil channel below is connected with cavity A, which is the oil inlet and outlet of cavity A. Therefore, the remaining hydraulic oil in this cavity only can be discharged through thus channel.

\section{Exploration of the oil discharging methods}

It can be found from the relationship between the structure and oil channels of the steering gear that some enterprises choose the natural oil discharging method, i.e. place the steering gear upside down, by which the hydraulic oil can not be completely discharged in terms of its structure. Even if shake 
the axle $\mathrm{A}$ in the figure 1 to move the piston to the left, the hydraulic oil in the cavity A can not be completely discharged (restricted by its structure, the piston can not be moved the leftmost end). Blowing oil discharging method also aims to place the steering gear upside down to discharge the oil. Although this method discharge oil fast, it is free of shaking the axle A during operation, thus the hydraulic oil in the cavity A can not be blew out, on the contrary, the remaining quantity will be increased. If place the steering gear upside down, and place the axle A down as shown in figure 1, and constantly blow the oil out, hydraulic oil in cavity B seems to be blew out, however, it is found from the experiment that air will be blew in from the oil inlet as blowing and then be directly discharged from the oil outlet, in consequence, the hydraulic oil will be drove to another side. Therefore, this method is infeasible to discharge the oil.

In 2007, two pumping units for steering gear were developed in a steering gear enterprise in Changchun City. This unit adopts vacuum extraction method, which refers to extract the remaining hydraulic oil in the internal steering gear through the pressure difference produced by negative pressure. One machine can be installed with two steering gears, and realize one circulation every 2 minutes. The whole working process is automatized. After oil extraction, the actual quantity of the remaining hydraulic oil in each product is less than $100 \mathrm{ml}$. This unit has been used in production for 7 years.

\section{Conclusion of the preliminary work}

Vacuum extraction-based pumping units for steering gear has been applied in actual production for 7 years, which solved the problem of environmental pollution during production, reduced workers' labor strength and greatly decreased the production costs for enterprises. However, problems have been found in application. Vacuum environment should be created for the vacuum extraction method, in which, one vacuum tank should be connected with vacuum pump, oil pumping pipe, oil exit pipe, liquid level sensor, trash-cleaning outlet, etc. Any untight connection or any failure will greatly influence the oil pumping effectiveness. Beside, the effectiveness will be greatly reduced if any connection between the oil pumping pipe \& blow down pipe and steering gear is untight. Therefore, the devices must be maintained frequently during operation. Long-term application of the vacuum pump may result in high failure rate as well, which consequently produced maintenance costs. Complex device is bound to increase the failure rate and maintenance costs. There are some human factors affecting the effectiveness of the oil pumping as well. For example, some workers may start to pump the oil before tightening the quick couplings on the oil inlet and outlet, and some workers may unload the workpieces before the oil pumping unit stopping. Therefore, it is necessary to formulate strict operation specification, and reduce the influence of human factors to the lowest as developing the devices.

\section{Exploration and practice of new oil discharging methods}

Traditional oil discharging methods is deficient in incomplete oil discharging, environment pollution, heavy labor intensity, etc. and these deficiencies are solved by the vacuum extraction method. However, due to the redundant and tedious devices and steps of the vacuum extraction method, there are many factors influencing the oil pumping effectiveness. Therefore, it is necessary to improve or redesign the unit.

It can be seen from the analysis on the structure and oil channels that the hydraulic oil is mainly existed in the left and right cavities, as shown in figure 1. These two cavities are completely separated by the piston in the middle, therefore, the oil in these two cavities must be discharged separately. To discharge the oil in the left cavity, the steering gear must be laid on the back, and make the oil channel connected with this cavity at rock bottom. While to discharge the oil in the right cavity, the axle A of the steering gear must be placed in a vertical state, by which the oil in the right cavity can be flow out from the lowest oil outlet. The connections and switching of all oil mouths of the steering gear are realized by the changing of the relative location between valve pocket and valve element, as shown in figure 2. However, oil mouths and gaps between valve pocket and valve element are extremely narrow, thus it is difficult for the hydraulic oil be discharged by its weight. It is conceived that firstly close the oil outlet by solenoid valve, and inflate compressed air into the steering gear through oil inlet. Place the steering gear on the back as 
discharging the oil in the left cavity, and make the oil channel of the left cavity on the lowest level. As the proportion of the air is less than that of the hydraulic oil, thus the compressed air in the left cavity will lie above the hydraulic oil. By this time, turn on the control circuit to instantly open the solenoid valve (the inflation valve connecting to the oil inlet is closed at the same time), by which compressed air will drive to discharge the oil through the oil outlet. The oil in the right cavity can be discharged by the same way, but the steering gear must be placed upside down. Repeat the above processes on each cavity for several times, and the remaining hydraulic oil will be discharged consequently.

It is theoretically feasible to use this method to discharge the oil, but in actual practice, time nodes should be emphasized, i.e. how long should the compressed air be injected and how long should the compressed air be kept and released? It should be kept for a while as the oil is of certain viscosity, and time for the oil to flow to gather to the lowest point must be reserved. Through a lot of experiments, we have concluded the optimum combination of all time sections. The recently developed oil discharging machine is able to discharge the oil within 2 minutes, which was controlled by PLC and realized automation in the whole process, as the vacuum extraction method does. Its remaining quantity is less than $90 \mathrm{ml}$ as weighted. This kind of method is called as airinflation oil discharging method.

Compared with the vacuum extraction method, the structure of the oil discharging machine of the air- inflation oil discharging method has been significantly simplified, which is free of a consecutive sets of institutions related to vacuum and greatly reduced the device costs. It is easier to maintain its machine but with equal oil discharging effectiveness. There are certain differences between the two methods in terms of the working efficiency. The vacuum extraction method is restricted by the capacity of the vacuum pump and able to operate two workpieces at most, while the air-inflation oil discharging method is able to operate several workpieces at one time only if the compressed air is sufficient on the scene.

\section{Conclusion}

Automobile industry is the pillar industry in our country, and its products quality and production costs have a direct impact on the national economy of our country. The production of every automobile component and part has a direct impact on the costs and quality of the entire automobile. Therefore, as a part of the automobile, steering gear is of great significance in reducing the production costs and improving the production quality. There are numerous steering gear manufacturers in China, and as a research blank in the technological equipment manufacturing, in-depth study on the pumping unit of the power steering gear has a certain practical significance. This research group developed two generations of oil discharging machines for power steering gear and applied into production, which filled the blank in this regard, improved the production process, and is of promotional value. However, there are numerous types of automobile power steering gears, it is necessary to develop and complete the oil discharging machines for different types of power steering gears, so as to make contributions to the development of China's automobile industry .

\section{References}

[1] liguangming:Optimal Design of Main Parameters for Pumping Unit of Automotive Power Steering Units [J]《Advanced Materials Research》 2011.4 